\title{
Growth in Rehabilitation: Dr. Geoff Fernie's Continuous Efforts to Make Injured Lives Worth Living
}

Peter Maitland

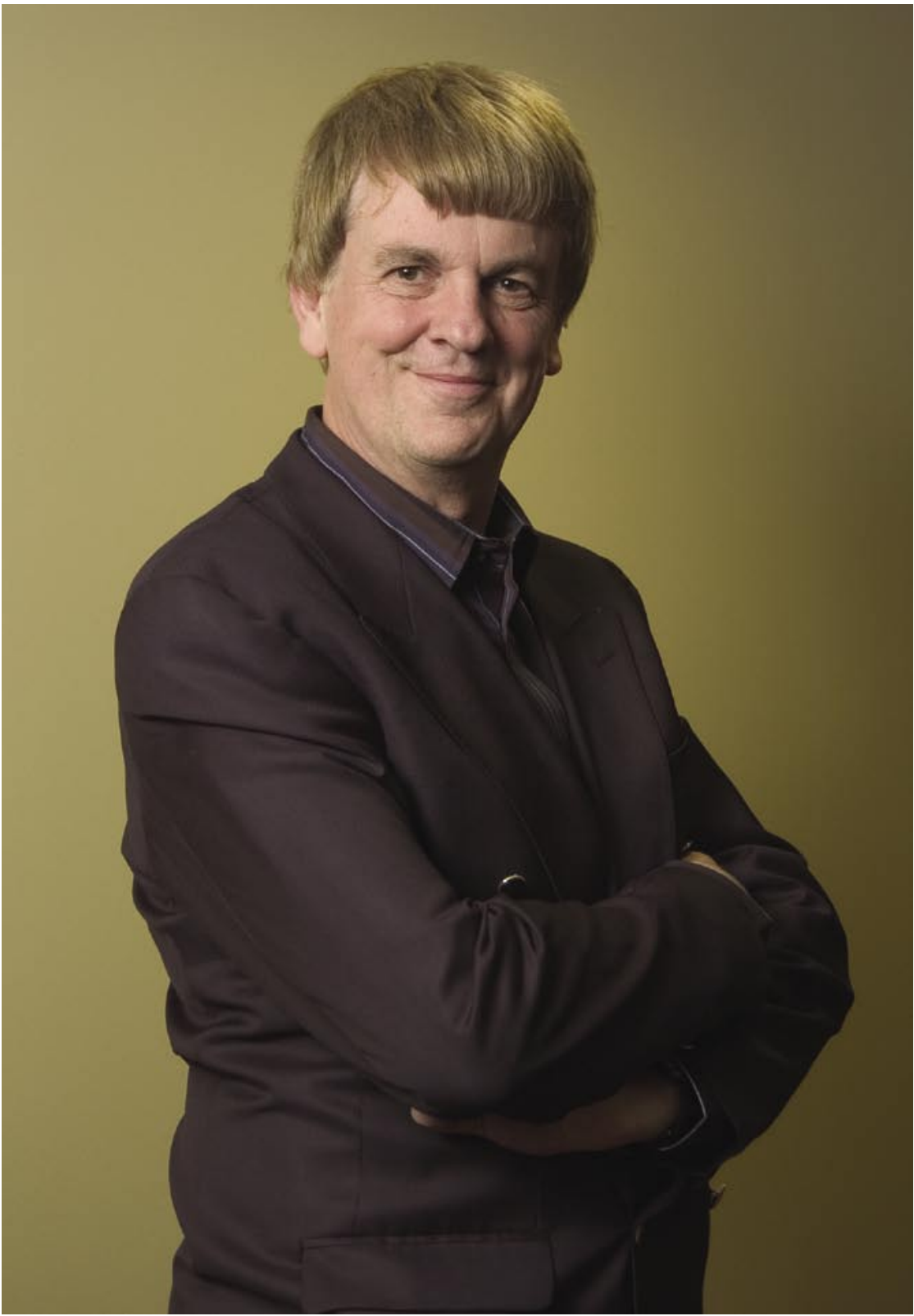

W hen it comes to medicine, surgeons and engineers aren't very different. Together, they can collaborate with the similar goal of turning daunting medical problems for patients into solutions. This desire for collaborative solutions continues to be Dr. Geoff Fernie's primary motivation as a biomedical engineer. As both vice-president of research with the Toronto Rehabilitation Institute and professor in the Department of Surgery at the University of Toronto, Dr. Fernie, who is funded by the Canadian Institutes of Health Research (CIHR), strives to produce inventions that will help those who suffer from problems related to aging, infections, disabilities or immobility. "To this day, the goal is to help people," Dr. Fernie says. "That's what we're here for."

\section{"To this day, the goal is to help people. That's what we're here for."}

The we is not restricted to surgeons and engineers but is related to everyone on a multidisciplinary level. After collaborating with a lot of researchers from a variety of different scientific backgrounds, Dr. Fernie has tried to provide inventive product solutions for patients and caregivers in hospitals around the world. 
These include, but are not limited to, SturdyLift, Toilevator, Robonurse and an anti-collision wheelchair. While some of these products are already in circulation, others are in a state of development. These products will become familiar objects in hospital wards and people's homes and, ultimately, will help patients make their injured lives worth living.

After completing his $\mathrm{PhD}$ at the University of Strathclyde in Glasgow, Scotland, Dr. Fernie came to Canada in 1973 to serve as research director at West Park Hospital in Toronto. Specifically, his goal was to establish an amputee centre at the long-term care hospital in collaboration with an orthopedic spine surgeon named Dr. John Kostuik. However, both men encountered one road block in terms of treatment for patients. "The reason why people weren't getting care was that there weren't great trained prosthetists and orthotists in the country," Dr. Fernie recalls. "There weren't people who knew how to make things and knew about the anatomy, physiology and behavioural issues with people. In other words, they didn't know how to marry their academic and practical skills."

It was at this point that, as a research fellow at the University of Toronto, Dr. Fernie decided to found a program at George Brown College dedicated to educating specialized Canadian prosthetists and orthotists. The educational program encouraged multidisciplinary collaboration as a means to improve life for those patients who live in long-term care situations. "Building capacity became another primary objective," he says.

Dr. Fernie's multidisciplinary interaction with others expanded. In 1983, he collaborated with Dr. Mike Jewett, a urologist, to research incontinence among older people and develop possible prevention methods.

Professional educators at the University of Toronto's Department of Surgery supported Dr. Fernie's encouragement of research collaboration, and, in 1986, he became the first full professor in the Department of Surgery who was not a surgeon.

That same year, Dr. Fernie became director of the Centre for Studies in Aging at Sunnybrook and Women's College Health Sciences Centre. "It was a hospital that was ideal for us," he recalls, "in that it had chronic care as well as long-term care and acute care for patients. Because it was a university centre, we could explore the healthcare system. We worked away in the basement there, and we grew."

While at Sunnybrook, Dr. Fernie and his growing research team started to develop inventions that would ultimately help patients in various hospitals across Canada. Some of them include SturdyLift and Toilevator.

\section{SturdyLift}

In the late 1980s, Dr. Fernie constructed SturdyLift as the first battery-operated overhead patient lift that could be shared among several beds in a hospital ward. The lift provided added safety, and reduced stress, for caregivers who try to move patients. These lifts have been installed in hospitals across North America.

\section{Toilevator}

Patients who are either disabled or morbidly obese have a difficulty using toilets because they find it hard to get up after they've used them. Toilevator solved that problem by adding a pedestal that fits under the toilet and providing a new extender for the soil pipe. Toilevator won Best New Canadian Product at the Canadian Hardware and Business Show in 2000 - and sales of the product continue to grow.

\section{Continued Change in Rehabilitation Research}

Because several inventions were being developed at Sunnybrook, Dr. Fernie and his team encountered space problems for their construction. That is why, in 2003, Dr. Fernie made a transition over to the Toronto Rehabilitation Institute ("Toronto Rehab"), a teaching hospital affiliated with the University of Toronto, to become vice-president of research. Toronto Rehab encourages rehabilitation knowledge and practice through research. Its goal is to help people who have suffered life-altering illnesses or injuries regain the skills they need to return to their communities.

According to Dr. Fernie, improvements and expansion in rehabilitation research require students from different scientific backgrounds who are interested in collaboration - not just invention. It's all part of a concerted effort to attract motivated researchers who want to take their potential rehabilitation inventions and transform them into something that can help patients and caregivers. "We need the latest scientific and engineering tools to do the work," Dr. Fernie says. "But we also need this high-technology environment to attract the brightest minds to come and do research in the field of rehabilitation."

\section{"We need the latest scientific and} engineering tools to do the work. But we also need this high-technology environment to attract the brightest minds to come and do research in the field of rehabilitation."

At Toronto Rehab, Dr. Fernie currently oversees a research program that includes 70 graduate students and 23 postdoctoral fellows in a variety of research fields (from engineering and computer science through to numerous clinical and social sciences). In short, he continues to create an environment where people with clinical backgrounds can learn about technology, and where technically minded people can learn about how to take care of patients. Under Dr. Fernie's supervision and 
support, students have been consistently encouraged to pursue technology and the transfer of inventions from the workshop to the commercial workplace.

While at Sunnybrook and Women's Health Sciences Centre, for example, one success story involved the development of gelFAST by Gilad Shoham. As a wearable access for hand hygiene, gelFAST has the potential to reduce the transmission of multi-drug-resistant hospital-acquired infections, such as methicillin-resistant Staphylococcus aureus (MRSA). Mr. Shoham founded his own gelFAST company called Medonyx Inc., and has since won the gold medal at the prestigious National Post Design Exchange Awards.

\section{Dr. Fernie will continue to significantly} change the landscape of rehabilitation research in Canada by creating and sharing with the world new knowledge, treatments and assistive technologies to improve and enhance the lives of older people and those living with disabling injury or illness.

Recently, thanks to CIHR-funded research relating to balance problems among older people, Drs. Brian Maki and Stephen Perry developed the Sole Sensor. As people age, there is a decrease in sensitivity among the sensory organs on the sole of feet. As a result, people are more likely to fall over. The Sole Sensor, designed as a shoe insole with a raised edge, decreases the loss of balance by enhancing sensory feedback in feet. The product, which will be easy to produce and inexpensive, should arrive on the marketplace during the winter of 2007.

Progress in rehabilitation research doesn't stop there, though. With the help of financing from public as well as private sector partner contributions, Toronto Rehab is in the middle of developing Intelligent Design for Adaptation, Participation and Technology (iDAPT), a 60,000-square-foot building that includes both research space and workshops.

As leader of iDAPT, Dr. Fernie will continue to significantly change the landscape of rehabilitation research in Canada by creating and sharing with the world new knowledge, treatments and assistive technologies to improve and enhance the lives of older people and those living with disabling injury or illness. iDAPT will also bring together individuals with varied disciplines and backgrounds who will address problem-based themes, rather than disciplinary or departmental lines. Scientists, research students, clinicians and social scientists will work alongside engineers and industrial designers to create a unique environment where investigators will study and develop solutions to these problems. iDAPT is expected to be completed by 2009 .

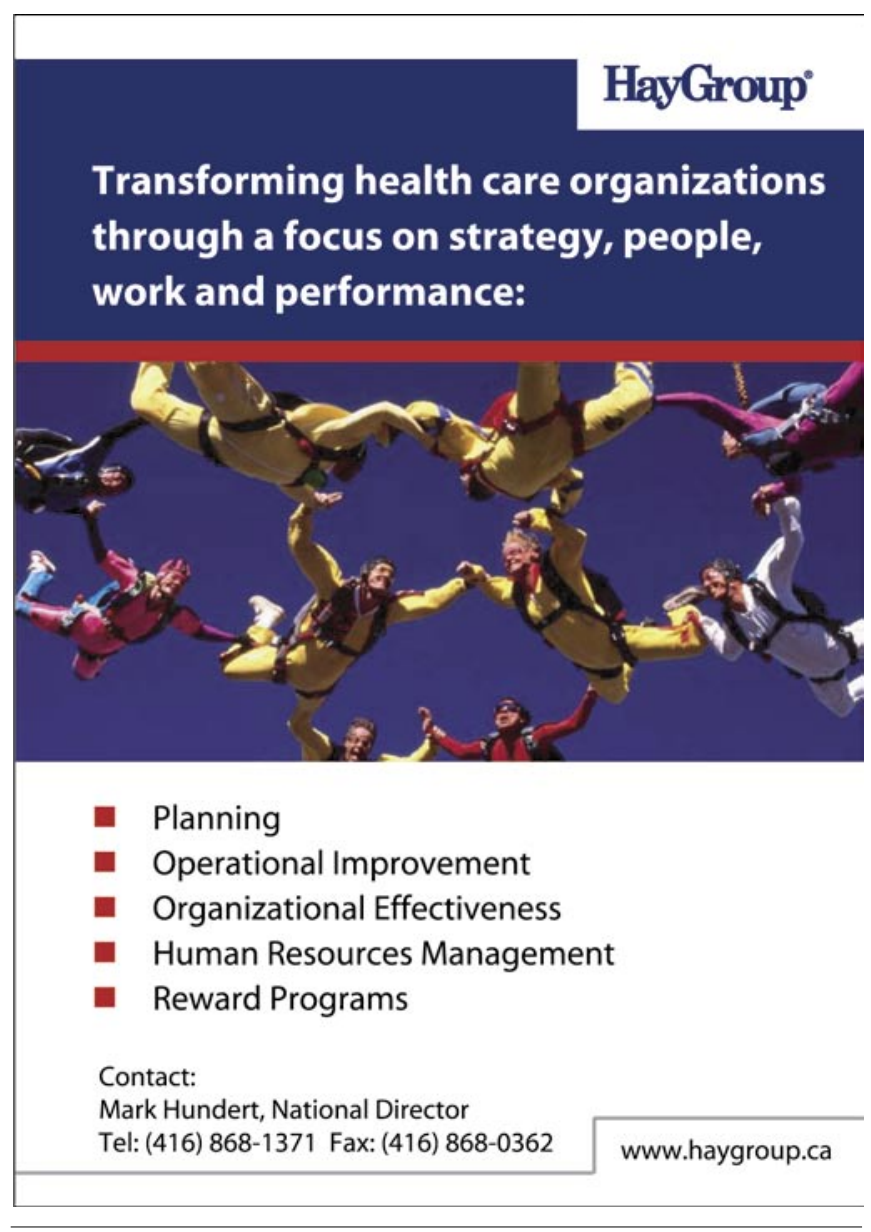

Other rehabilitation inventions remain in the pipeline. One primary example is a robot called Robonurse. A great deal of nurses and other caregivers suffer injuries in attempts to lift and move patients; Robonurse would help in this kind of movement with its capacity to transport up to 360 kilograms at a time. The CIHR-funded product is currently in its third prototype and should make its way to hospitals shortly.

Dr. Fernie is also helping develop an anti-collision wheelchair that will stop automatically when faced with an obstacle. Using sensors that are connected to a computerized system, the wheelchair allows patients who are cognitively impaired, due to stroke or dementia, the possibility to move around safely.

According to Dr. Fernie, in order to make sure that rehabilitation research keeps progressing, students and the general public need to recognize its overall potential. And keeping a patient in mind from a personal perspective will always help. "It's a challenge to help rehabilitation grow," says Dr. Fernie. "People must not only be aware of the reports of saving lives; they must also make lives worth living once they've had their lives saved." HQ

\section{About the Author}

Peter Maitland is a writer-editor in ClHR's Marketing and Communications Division. 